\title{
Distinct patterns of circulating endothelial cells in pulmonary hypertension
}

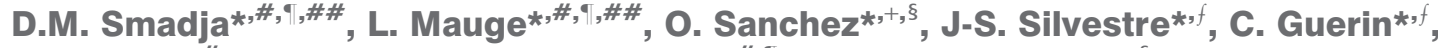 \\ A. Godier*,\#,**, P. Henno ${ }^{\star,+}$, P. Gaussem ${ }^{\star, \#, \uparrow}$ and D. Israël-Biet* ${ }^{*,+}$
}

ABSTRACT: The respective abundance of circulating endothelial cells and endothelial progenitor cells may reflect the balance between vascular injury and repair. As pulmonary arterial hypertension (PAH) and chronic thromboembolic pulmonary hypertension (CTEPH) can share features of pulmonary remodelling, we postulated that the two disorders might be associated with different types of pulmonary endothelial dysfunction.

We studied 25 consecutive patients undergoing cardiac catheterisation for suspected pulmonary hypertension. Nine patients had PAH, nine had CTEPH, and seven had normal pulmonary arterial pressure and served as controls. Circulating endothelial cells were isolated with CD146-coated beads. CD34+CD133+ cell and endothelial progenitor cell numbers were respectively determined by flow cytometry and cell culture, in peripheral vein and pulmonary artery blood. Plasma levels of soluble vascular endothelial growth factor (VEGF), soluble Eselectin and soluble vascular cell adhesion molecule (sVCAM) were measured by ELISA.

No difference in progenitor counts or VEGF levels was found across the three groups. Compared to controls, circulating endothelial cell numbers were significantly increased in PAH but not in CTEPH, in keeping with the elevated soluble E-selectin and SVCAM levels found in PAH alone.

In conclusion, $\mathrm{PAH}$, in contrast to $\mathrm{CTEPH}$, is associated with markers of vascular injury (circulating endothelial cells, soluble E-selectin and sVCAM) but not with markers of remodelling (endothelial progenitor cells, CD34+CD133+ cells and VEGF).

KEYWORDS: Circulating endothelial cells, circulating progenitor cells, endothelial progenitor cells, pulmonary hypertension

$\mathbf{V}$ ascular remodelling is observed in several disorders characterised by increased pulmonary vascular resistance and pulmonary hypertension. Recently, the 4th World Symposium on pulmonary hypertension proposed an updated clinical classification [1], aimed at grouping together different disease manifestations sharing similar pathophysiological mechanisms, clinical features and therapeutic management. Pulmonary arterial hypertension (PAH, group 1) is a complex and rapidly progressive disorder: without treatment, right heart failure and death ensue within a median of 2.8 yrs [2]. Vessel wall remodelling and cellular hyperproliferation are the hallmarks of severe disease [3, 4]. Plexiform lesions in PAH are due to abnormal and disorganised proliferation of monoclonal endothelial cells that obstruct and eventually occlude the vascular lumen [5-7]. Chronic thromboembolic pulmonary hypertension $(\mathrm{CTEPH})$ is characterised by intraluminal thrombus organisation, fibrous stenosis and, in some cases, complete obliteration of pulmonary arteries [1]. Pulmonary endarterectomy is the treatment of choice for CTEPH and is the only potentially curative option. However, progressive pulmonary vascular remodelling in the nonobstructed vascular bed is thought to be the main pathophysiological mechanism of CTEPH $[8,9]$.

Endothelial cell dysfunction is a hallmark both of $\mathrm{PAH}$ and of pulmonary hypertension secondary to congenital heart disease [10]. Most relevant human data have been obtained with surgical lung biopsy material, through histomorphological studies and generation of vascular structural cell lines. Because lung biopsy is highly invasive, cellular biomarkers of pulmonary vascular remodelling and dysfunction could be very useful for diagnosis and/or prognostication. The ratio between circulating endothelial cells (CECs) and endothelial progenitor cells has raised considerable interest as a marker of the balance between endothelial damage and regeneration, and therefore as a noninvasive marker of vascular dysfunction [11].
AFFILIATIONS

*Université Paris Descartes,

\#Inserm UMR-S 765, Faculté de Pharmacie,

"Assistance Publique-Hôpitaux de Paris, Hôpital Européen Georges

Pompidou, Service d'hématologie biologique

+UPRES EA4068, UFR Biomédicale des Saints Pères,

${ }^{\S}$ Assistance Publique-Hôpitaux de Paris, Hôpital Européen Georges

Pompidou, Service de pneumologie,

${ }^{f}$ PARis-Cardiovascular research

Centre; Inserm U970,

**Assistance Publique-Hôpitaux de Paris, Hôpital Hôtel Dieu, Service d'Anesthésie et réanimation, Paris, France.

\#\# Both authors contributed equally to this study.

\section{CORRESPONDENCE}

D.M. Smadja

Assistance Publique-Hôpitaux de

Paris

Hôpital Européen Georges Pompidou Service d'hématologie biologique

20 rue Leblanc

75015 Paris

France

E-mail: david.smadja@egp.aphp.fr

Received:

Aug 182009

Accepted after revision:

April 092010

First published online:

April 222010 
CECs are noninvasive markers of vascular damage, remodelling and dysfunction [12]. CECs are present at very low levels in healthy subjects and have been described as a marker of systemic vascular dysfunction [11]. Peripheral CEC counts are elevated in human primary and secondary pulmonary hypertension [13], including pulmonary hypertension secondary to congenital heart disease [14]. Several populations of bone marrow-derived cells expressing endothelial markers migrate to sites of neovascularisation [15]. Hill's method of counting endothelial progenitor cells is now available in the form of a commercial kit that identifies so-called "CFU-EC" (endothelial cell colony-forming units), namely endothelial cells expressing myeloid markers [16]. The peripheral blood CFU-EC count is low in patients with cardiovascular risk factors [16]. CFU-EC numbers are diminished in chronic obstructive pulmonary disease and correlate negatively with disease severity [17]. Angiogenic gene therapy and endothelial progenitor cells transplantation were recently shown to attenuate pulmonary hypertension in a rat model [18-20], while WANG et al. [21] found that endothelial progenitor cell transplantation improved exercise capacity and pulmonary haemodynamics in patients with idiopathic pulmonary hypertension. However, reports on endothelial progenitor cell numbers in pulmonary hypertension are controversial [22-24], but CEC and endothelial progenitor cell numbers have not yet been compared in the same population of adults with pulmonary hypertension.

As the endothelial phenotype is strongly modified in pulmonary hypertension, we postulated that the circulating endothelial compartment, i.e. CEC and CFU-EC, might be differently modulated in $\mathrm{PAH}$ and CTEPH. We therefore determined CEC, CD34+CD133+ cell and CFU-EC numbers in both peripheral venous blood and pulmonary arterial blood from subjects with PAH and CTEPH. We then analysed the results with respect to the clinical and haemodynamic characteristics of the two disorders and to soluble biomarkers of endothelial damage and regeneration.

\section{PATIENTS AND METHODS}

\section{Study population}

The study was approved by the Necker ethics committee (Comité de protection des personnes Ile de France II, Paris, France), and signed informed consent was obtained from all the patients and controls. We enrolled 25 consecutive patients undergoing right heart cardiac catheterisation at Georges Pompidou European Hospital (Paris, France) during routine management of suspected pulmonary hypertension, in keeping with current guidelines. Right atrial pressure, pulmonary artery pressure $(P \mathrm{pa})$, pulmonary artery wedge pressure, cardiac output and pulmonary vascular resistance (PVR) were measured in each patient during catheterisation. Pulmonary hypertension was defined as a mean pulmonary artery pressure $\left(\bar{P}_{\text {pa }}\right)>25 \mathrm{mmHg}$ at rest and a pulmonary artery wedge pressure $<15 \mathrm{mmHg}$ during cardiac catheterisation [25]. Pulmonary hypertension was confirmed in 18 patients and ruled out in seven patients. Following the updated clinical classification of pulmonary hypertension and current guidelines, these 18 patients were classified as having $\mathrm{PAH}(\mathrm{n}=9$; idiopathic $(n=3)$, associated with connective tissue disease $(n=3)$, portal hypertension $(n=2)$ or HIV infection $(n=1))$, or
CTEPH $(n=9)$. The seven patients who underwent catheterisation because they had echocardiographic signs of pulmonary hypertension but whose $P$ pa was found to be normal served as controls. All patients underwent the 6-min walk test (6MWT). All patients with pulmonary hypertension had acute vasodilator testing with inhaled nitric oxide (NO) 10 ppm for $10 \mathrm{~min}$, as recommended by the recent European guidelines for the diagnosis and treatment of pulmonary hypertension [26]. Only one patient with $\mathrm{PAH}$ had an acute response, defined as a reduction in $\bar{P}_{\text {pa }} \geqslant 10 \mathrm{mmHg}$, reaching an absolute $\bar{P}_{\text {pa }}$ of $\leqslant 40 \mathrm{mmHg}$ with increased or unchanged cardiac output. The BMPR2 gene had been analysed in only one patient with idiopathic PAH and was found to be normal. Three patients with PAH were receiving specific drug therapy at the time of right heart catheterisation: one patient with idiopathic $\mathrm{PAH}$ received a combination of continuous intravenous prostacyclin, sildenafil and bosentan, while the other two patients received bosentan monotherapy. Two patients with inoperable CTEPH were receiving specific drug therapy at the time of right heart catheterisation, consisting of a combination of subcutaneous treprostinil, bosentan and sildenafil in one case, and bosentan monotherapy in the other case. Three patients were evaluated twice (at diagnosis and after 3 months of firstline bosentan vasodilator therapy).

\section{CEC isolation and counting}

Peripheral venous and pulmonary arterial blood samples were collected on EDTA during cardiac catheterisation. For CEC quantification and CFU-EC and CD34+CD133+ counts, the first $\mathrm{mL}$ of blood was discarded to avoid collecting endothelial cells dislodged by puncture. CECs were counted by an operator who was unaware of the patients' clinical status. CECs in whole blood were immunocaptured at $4{ }^{\circ} \mathrm{C}$ with magnetic beads (Dynabeads M-450; Dynal ${ }^{\circledR}$, Invitrogen, Cergy-pontoise, France) coated with S-Endo 1 (Biocytex ${ }^{\circledR}$, Marseille, France), a monoclonal antibody (mAb) against the endothelial antigen CD146. To avoid nonspecific leukocyte binding to the beads, the cell suspensions were flushed vigorously through the pipette tip during the washing steps and then suspended in acridine orange $\left(3 \mu \mathrm{g} \cdot \mathrm{mL}^{-1}\right.$ in PBS; Sigma-Aldrich ${ }^{\circledR}$, SaintQuentin Fallavier, France) before counting under a fluorescence microscope $\left(\lambda_{\text {exc }} 490 \mathrm{~nm}\right)$. CECs were identified as $>$ $20-\mu \mathrm{m}$ diameter cells bearing $>10$ beads, or as cells with $<10$ beads but with a well-preserved and recognisable morphology (clear nucleus in a well-defined cytoplasm, and a size compatible with that of endothelial cells). The number of cells in aggregates was determined from the number of nuclei or spherical rosette features. The endothelial nature of the cells thus isolated was confirmed by measuring lectin Ulex europaeus agglutinin (UEA)1 expression.

\section{Flow cytometric quantification of circulating CD34+CD133+ progenitor cells in pulmonary hypertension}

CD34+CD133+ cells were quantified in EDTA-anticoagulated peripheral blood and pulmonary arterial blood by means of two-colour flow cytometry on a FACScalibur device (BectonDickinson, Le Pont de Claix, France). Briefly, $100 \mu \mathrm{L}$ of blood was incubated with $10 \mu \mathrm{L}$ of phycoerythrin-cyanin-5-conjugated anti-human CD34 mAb (Beckman-Coulter, Villepinte, France) and $10 \mu \mathrm{L}$ of phycoerythrin (PE)-conjugated anti-humanCD133 mAb (Miltenyi Biotec, Bergisch-Gladbach, Germany). 
Nonimmune mAbs of the same isotype as the immune mAbs and provided by the same manufacturer were used as controls. The number of positive peripheral blood cells was determined by two-dimensional side-scatter fluorescence dotplot analysis after gating on the lymphocyte population. Each analysis comprised 30,000 events. The number of CD34+ CD133+ cells was normalised and expressed per $1 \times 10^{5}$ circulating lymphocytes.

\section{Granulocyte-macrophage colony-forming unit quantification}

Mononuclear cells $\left(4 \times 10^{5}\right.$ per dish) were seeded in methylcellulose plates (Stem alpha 1F; Stem alpha ${ }^{\circledR}$, Saint-Genis l'Argentière, France) in medium supplemented with stem cell factor, granulocyte colony-stimulating factor, granulocytemacrophage colony-stimulating factor, erythropoietin, interleukin (IL)-3, and IL-6. Granulocyte-macrophage colony-forming units (CFU-GM) were counted after 14 days of culture, by phase-contrast microscopy.

Flow cytometric quantification of CD34+CD133+KDR+ cells CD34+CD133+KDR+ cells were quantified in EDTA-anticoagulated peripheral blood by flow cytometry on a BD-LSRII cytometer (Becton-Dickinson). Briefly, after Ficoll gradient, $100 \mu \mathrm{L}$ of mononuclear cell suspension was incubated with $10 \mu \mathrm{L}$ of fluorescein isothiocyanate (FITC)-conjugated antihuman CD34 mAb (Beckman-Coulter), $10 \mu \mathrm{L}$ of PE-conjugated anti-human-CD133 mAb (Miltenyi Biotec) and $10 \mu \mathrm{L}$ of allophycocyanin (APC)-conjugated anti-human KDR mAb (Becton-Dickinson). Nonimmune mAbs of the same isotype as the immune mAbs and provided by the same manufacturer were used as controls.

\section{Sorting of CD34+CD133+ cells}

CD34+CD133+ cells were sorted with a BD-FACSAriaII ${ }_{\circledast}$ flow cytometer (Becton-Dickinson). Briefly, after Ficoll separation,
$10 \mu \mathrm{L}$ of FITC-conjugated anti-human CD34 mAb (BeckmanCoulter) and $10 \mu \mathrm{L}$ of PE-conjugated anti-human-CD133 $\mathrm{mAb}$ (Miltenyi Biotec) were incubated with $2 \times 10^{6}$ mononuclear cells. After staining, cells were resuspended in PBS- $0.5 \%$ bovine serum albumin (BSA) at $1 \times 10^{6}$ cells per $100 \mu \mathrm{L}$. The suspension was filtered through BD tubes with cell strainer caps (Becton-Dickinson) just before cell sorting. CD34+CD133+ cells were collected in tubes coated with BSA.

\section{Quantification of CFU-EC}

EDTA-anticoagulated blood was diluted 1:1 with PBS, $0.2 \mathrm{M}$ EDTA and overlaid on Histopaque-1077 (Sigma-Aldrich). Cells were centrifuged at $100 \times g$ for $20 \mathrm{~min}$. Mononuclear cells (MNCs) were collected and washed three times in PBS, $0.2 \mathrm{M}$ EDTA. CFU-EC were cultured with the EndoCult ${ }$ Liquid Medium kit (StemCell Technologies, Vancouver, BC, Canada) as recommended by the manufacturer. Briefly, MNCs were resuspended in complete EndoCult ${ }_{\circledast}$ medium and seeded at $5 \times 10^{6}$ cells $^{-w^{-1}}{ }^{-1}$ in fibronectin-coated tissue culture plates (Becton-Dickinson). After $48 \mathrm{~h}$, nonadherent cells were collected and plated in Endocult ${ }$ buffer at $10^{6}$ cells $^{*}$ well ${ }^{-1}$ in $24-$ well fibronectin-coated plates, and colonies were counted after another 3 days.

\section{Measurement of soluble endothelial biomarkers}

Peripheral venous and pulmonary arterial blood was collected during cardiac catheterisation in tubes containing $0.105 \mathrm{M}$ sodium citrate $(1: 9 v / v)$. Plasma was obtained by double centrifugation at $2,300 \times g$ for $10 \mathrm{~min}$ and was immediately placed at $-80^{\circ} \mathrm{C}$ until use. Plasma levels of vascular endothelial growth factor (VEGF), soluble E-selectin and soluble vascular cell adhesion molecule (sVCAM) were measured with highly sensitive ELISAs as recommended by the manufacturer (R\&D Systems, Minneapolis, MN, USA).

\section{TABLE 1 Characteristics of the patients}

\begin{tabular}{|c|c|c|c|}
\hline Subjects $n$ & 7 & 9 & 9 \\
\hline Sex ratio male/female $n$ & $3 / 4$ & $5 / 4$ & $5 / 4$ \\
\hline NYHA I-II/III-IV n & $7 / 0$ & $5 / 4$ & $5 / 4$ \\
\hline 6MWT m & $505(495-517)$ & $475(347-530)$ & $442(383-450)$ \\
\hline Ppa,syst mmHg & $34(27-37)$ & $66(51-80)$ & $60(50-69)$ \\
\hline Ppa,diast $\mathrm{mmHg}$ & $14(10-16)$ & $24(21-32)$ & $20(18-28)$ \\
\hline CI L. $\min ^{-1} \cdot \mathrm{m}^{-2}$ & $3.7(2.8-4.0)$ & $2.4(2.2-3.9)$ & $2.4(2.2-2.6)$ \\
\hline PVRi UI. $\mathrm{m}^{-2}$ & $3.5(2.3-3.7)$ & $10.2(7.5-21.5)$ & $10.6(6.1-14.7)$ \\
\hline Acute responder ${ }^{\#} \mathbf{n}$ & & 1 & 0 \\
\hline
\end{tabular}

Data are presented as median (interquartile range), unless otherwise stated. PAH: pulmonary arterial hypertension; CTEPH: chronic thromboembolic pulmonary hypertension; NYHA: New York Heart Association; 6MWT: 6-min walk test; Pra: right atrial pressure; $\bar{P}_{\mathrm{pa}}$ mean pulmonary artery pressure; Ppa,syst: systolic pulmonary

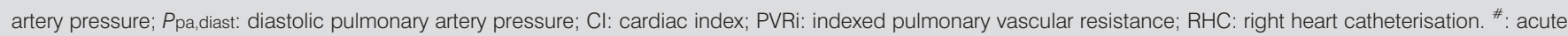
response to inhaled nitric oxide testing. 

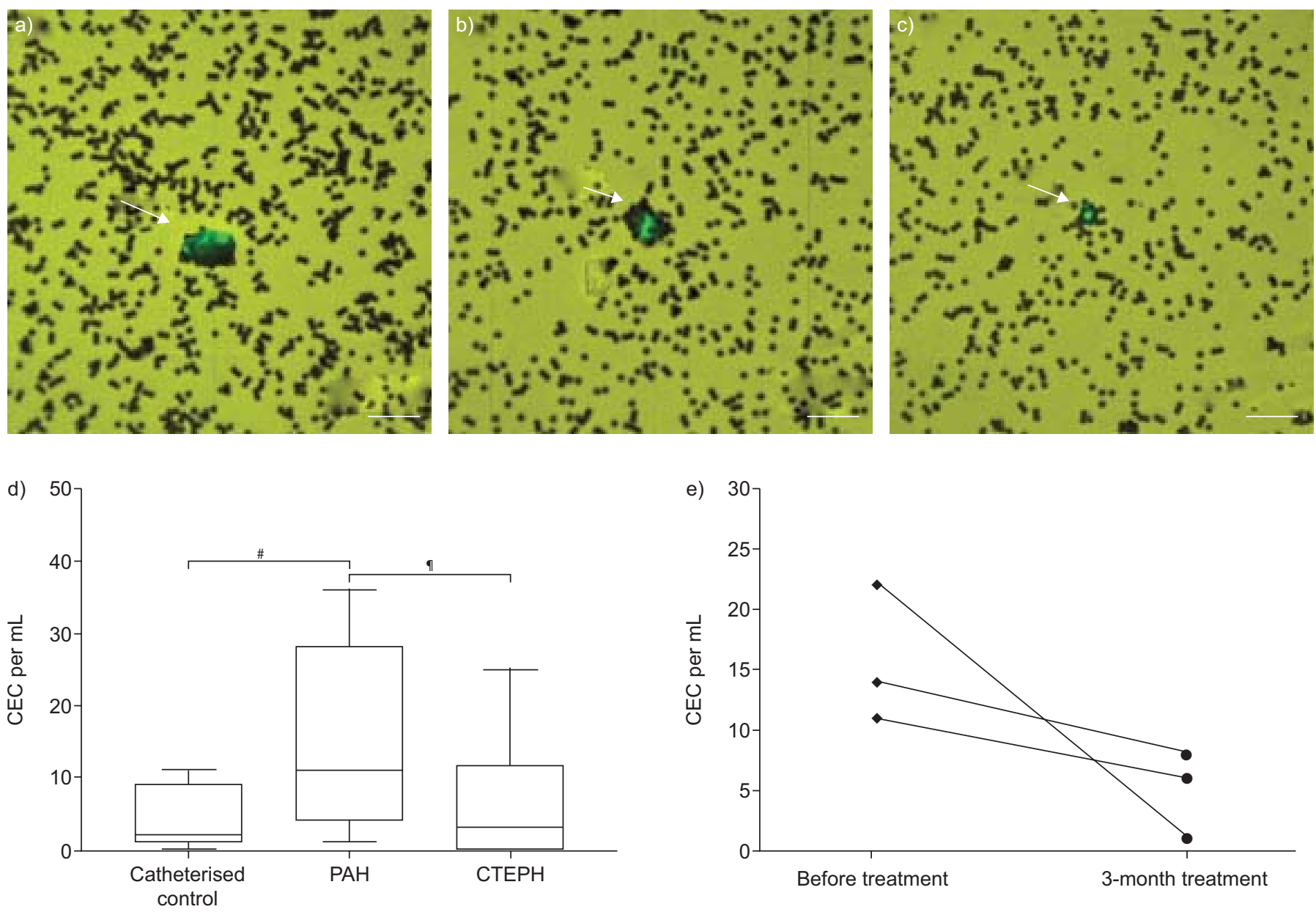

FIGURE 1. Circulating endothelial cell (CEC) morphology and counts in peripheral venous blood of patients with pulmonary hypertension. a-c) Identification of CEC by fluorescent microscopy after immunomagnetic separation and staining with Ulex europaeus agglutinin 1 (UEA1) or acridine. The arrows indicate a) a CEC after staining with UEA1; b) a CEC after staining with acridine; and c) a lymphocyte after staining with acridine. Scale bars $=30 \mu \mathrm{m}$. d) CEC counts in peripheral venous blood of pulmonary arterial hypertension (PAH) and chronic thromboembolic pulmonary hypertension (CTEPH) patients. CEC counts were significantly increased in PAH. ${ }^{\#}: p=0.01 ; ": p=0.04$. e) CEC quantification in three PAH patients before $(\bullet)$ and after $(\bullet)$ a 3-month course of first-line bosentan therapy.

\section{Statistical analysis}

The nonparametric Mann-Whitney U-test was used to identify differences in peripheral markers between the two patient groups and the controls. A paired t-test was used to determine the significance of differences between CEC and CD34+CD133+ numbers in the two types of blood sample. Statistical significance was assumed at $p \leqslant 0.05$. All statistical tests were performed with the Stat View software package (SAS, Cary, NC, USA).

\section{RESULTS}

\section{Study population}

The patients' and controls' clinical and haemodynamic characteristics are summarised in table 1 . The patients with $\mathrm{PAH}$ and CTEPH were comparable in terms of demographic and haemodynamic parameters $\left(\bar{P}_{\mathrm{pa}}, \mathrm{PVR}\right.$ and walking test values: $\mathrm{p}=0.54,0.38$ and 0.87 , respectively).

\section{CEC numbers}

Immunomagnetically isolated CECs were observed after staining with the fluorescent probe acridin orange or UEA1 (fig. 1a and b). No significant difference in CEC counts was noted between the two types of blood sample in any of the three groups of subjects (table 2). Peripheral CEC counts were normal ( $<10$ CEC per $\mathrm{mL}$ in healthy adults, as defined by the consensus protocol [12]) in both the controls and the patients with CTEPH. In contrast, the mean CEC count was six-fold higher in PAH patients than in controls $(p=0.01)$ and four-fold higher than in CTEPH patients $(p=0.04)$ (table 2 and fig. $1 d$ ). Moreover, we found no correlation between CEC counts and the New York Heart Association classification or the following haemodynamic data: $\bar{P}_{\text {pa }}\left(-5.2 \times 10^{-19}\right.$; Spearman correlation coefficient $\mathrm{p}=0.99), \quad$ Ppa,systolic $(0.139 ; \mathrm{p}=0.37), \quad P$ pa,diastolic (0.142; $\mathrm{p}=0.58), 6 \mathrm{MWT}(0.3571 ; \mathrm{p}=0.38)$, cardiac index $(0.4185 ; \mathrm{p}=0.27)$ or PVR $(-0.2167 ; \mathrm{p}=0.58)$. Three PAH patients could be re-evaluated 3 months after diagnosis and initiation of specific treatment with bosentan (Tracleer; Actelion Pharmaceuticals, Paris, France), and a marked decrease in CEC counts was observed (fig. 1e).

\section{Circulating CD34+CD133+ progenitor cell numbers}

No significant difference in CD34+CD133+ counts was found according to the sampling site (table 2), and the peripheral 


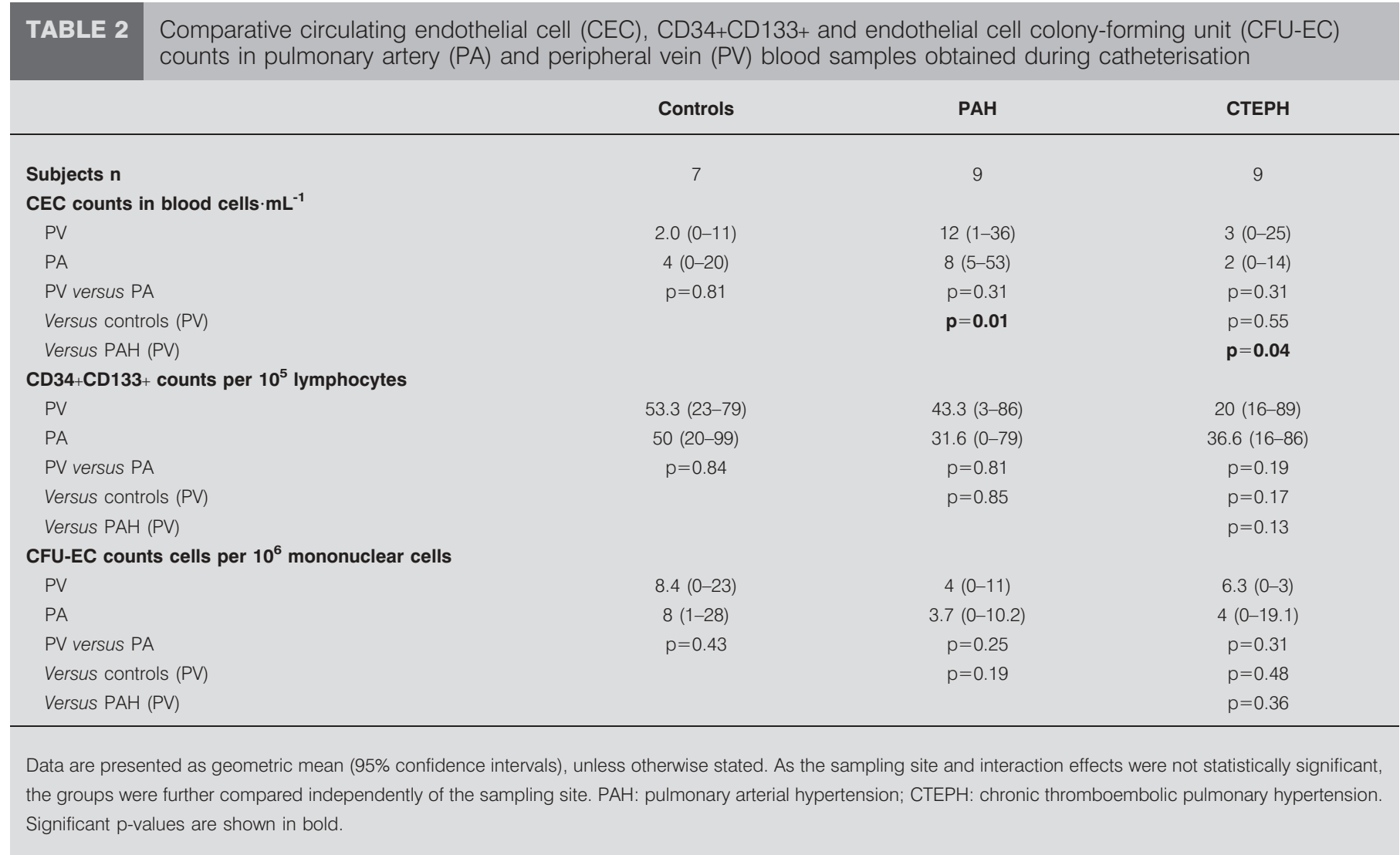

CD34+CD133+ counts did not differ significantly across the three groups (controls, PAH and CTEPH) (fig. 2a). CD34+CD133+ cells were also quantified in two other control groups (48 healthy volunteers and 30 patients without cardiovascular risk factors who were scheduled for valve surgery), and no difference was observed between these groups and the study control group (fig. 2a). CD34+CD133+ cell counts were not modified by specific therapy in the three treated patients with $\mathrm{PAH}$ (data not shown). A subset of CD34+CD133+ cells (0.4\%) expressed the VEGF receptor 2 (KDR), in contrast to the CD34+CD133- population, which contained only $0.03 \%$ of cells expressing KDR (fig. 2c). CD34+CD133+-sorted cells were further able to differentiate into CFU-GM in a clonogenic assay, in line with their other features of progenitor cells (fig. 2c). CFU-GM were quantified in each group and, in line with the CD34+CD133+ cell counts, no difference was observed between the patients and controls $(\mathrm{p}=0.91$ and $\mathrm{p}=0.66$, respectively, for $\mathrm{PAH}$ and CTEPH versus controls; and $\mathrm{p}=0.68$ for $\mathrm{PAH}$ versus $\mathrm{CTEPH}$ ) (fig. $2 \mathrm{~b}$ ).

\section{CFU-EC numbers}

On day 5 of culture, CFU-EC colonies consisted of elongated sprouting cells radiating from a central core of round cells (fig. 3a). These cells expressed von Willebrand factor (fig. 3b), KDR and CD31 (fig. $3 \mathrm{c}$ and d) and were able to secrete large amounts of the angiogenic growth factors VEGF and stromal derived factor-1 (fig. 3d). No difference in CFU-EC numbers was found between the two sampling sites in any of the three groups (table 2). Peripheral CFU-EC counts were similar in the three groups (median (range): $4(0-11), 6(0-37)$ and $8(0-23)$
CFU-EC per $10^{6}$ mononuclear cells in PAH and CTEPH patients and controls, respectively; all comparisons nonsignificant) (table 2 and fig. 3e). CFU-EC counts were not influenced by specific treatment in the three $\mathrm{PAH}$ patients concerned.

\section{VEGF, soluble E-selectin and sVCAM plasma levels}

VEGF levels were similar in the three groups (median (range): 20.7 (12.6-115.2), 33.4 (33.3-52.6) and 29.6 (13.9-71.2) $\mathrm{pg} \cdot \mathrm{mL}^{-1}$ in PAH and CTEPH patients and controls, respectively; all comparisons nonsignificant) (fig. 4a). By contrast, soluble Eselectin levels were significantly higher in $\mathrm{PAH}$ patients than in CTEPH patients $(p=0.04)$ and in the controls $(p=0.03)$ (median (range): 45 (32-57), 33 (19-53) and 29 (14-71) $\mathrm{ng} \cdot \mathrm{mL}^{-1}$, in $\mathrm{PAH}$ and $\mathrm{CTEPH}$ patients and controls, respectively) (fig. $4 \mathrm{~b}$ ). In line with the results for soluble E-selectin, levels of sVCAM, another biomarker of endothelial lesions and/or activation, were significantly higher in $\mathrm{PAH}$ patients than in CTEPH patients $(p=0.02)$ and in the controls $(p=0.006)$ (median (range): 1,167 (455-3,454), $544(402-1,347)$ and 486.5 $(279-1,084) \mathrm{ng} \cdot \mathrm{mL}^{-1}$, in PAH and CTEPH patients and controls, respectively) (fig. $4 \mathrm{c}$ ).

\section{DISCUSSION}

This is the first study to quantify the different components of the circulating endothelial compartment (CEC, CFU-EC and CD34+CD133+) and to compare their abundance in two different forms of pulmonary hypertension. In PAH, contrary to CTEPH, we found elevated CEC numbers and high levels of soluble E-selectin and sVCAM, both of which are recognised 

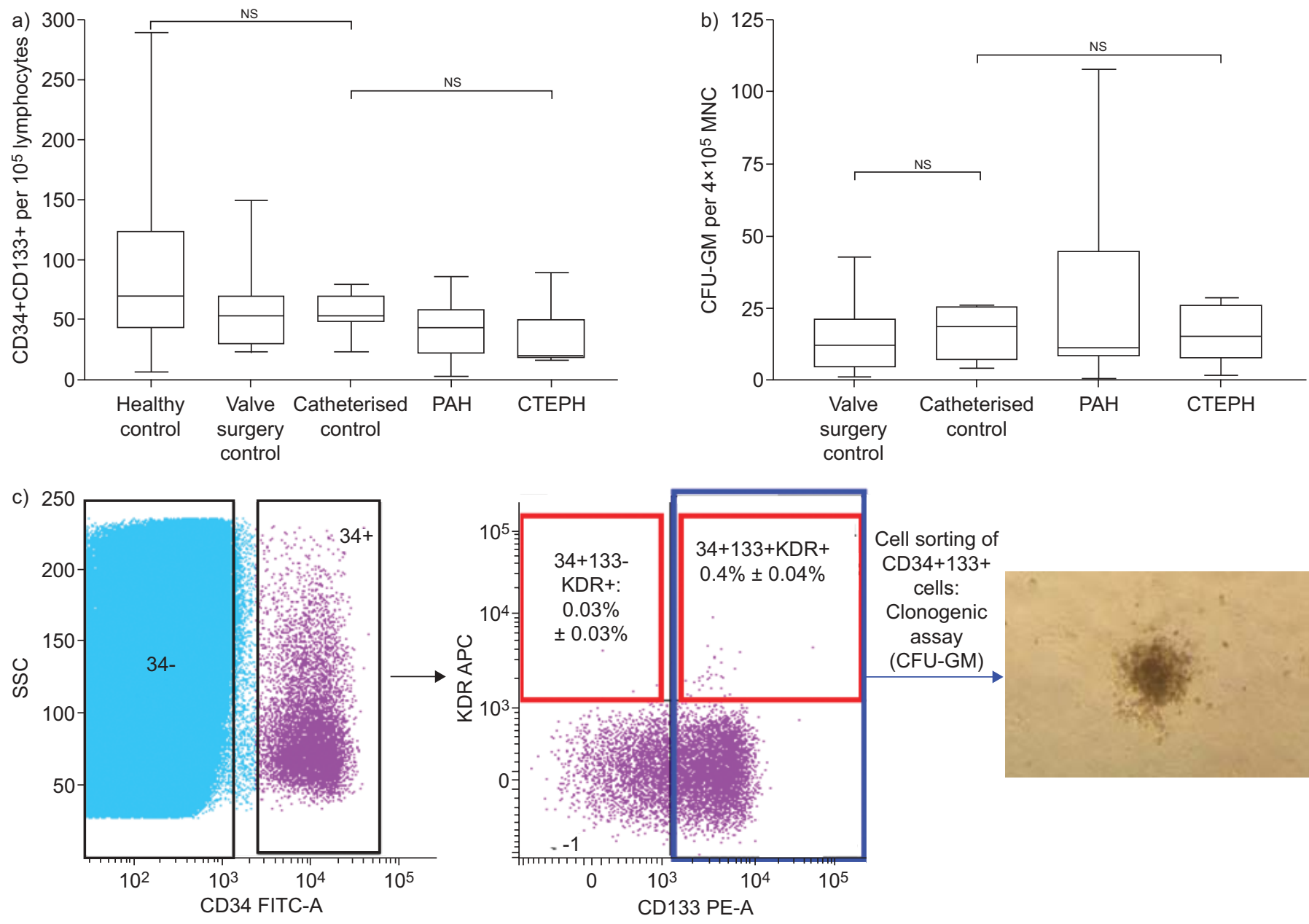

FIGURE 2. CD34+CD133+ counts in peripheral venous blood in pulmonary arterial hypertension (PAH) and chronic thromboembolic pulmonary hypertension (CTEPH) patients. a) $\mathrm{CD} 34+\mathrm{CD} 133+$ were quantified by flow cytometry. The patients did not differ significantly from the controls. $(p=0.85$ and $p=0.17$, respectively, for PAH and $\mathrm{CTEPH}$ versus controls and $p=0.13$ for PAH versus CTEPH). NS: nonsignificant. b) Granulocyte-macrophage colony-forming units (CFU-GM) were quantified with a clonogenic assay (methyl cellulose). The patients did not differ significantly from the controls ( $p=0.91$ and $p=0.66$, respectively, for $\mathrm{PAH}$ and $\mathrm{CTEPH}$ versus controls and $p=0.68$ for $\mathrm{PAH}$ versus CTEPH). MNC: mononuclear cell. c). $0.4 \%$ of $\mathrm{CD} 34^{+} \mathrm{CD} 133^{+}$were positive for vascular endothelial growth factor receptor 2 (KDR). CD34+CD133+ cells sorted with a BD-

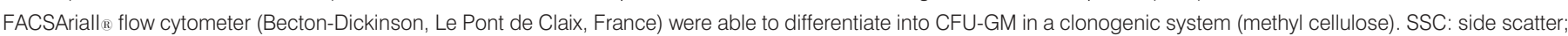
FITC: fluorescein isothiocyanate; APC: allophycocyanin; PE: phycoerythrin.

markers of vascular damage or activation, whereas markers of endothelial remodelling (CFU-EC, CD34+CD133+and VEGF) were normal in both settings.

One important result of this study is the similar numbers of CEC, CD34+CD133+ and CFU-EC in peripheral and pulmonary blood. When we started this study, we had no knowledge of CEC clearance from peripheral blood, and therefore studied local release of CEC in blood sampled from the pulmonary artery. We were surprised to find that peripheral blood gave identical results. However, in a previous study of children with pulmonary hypertension secondary to congenital heart disease, we also found similar CEC numbers in peripheral blood and pulmonary artery blood [14]. This suggests that peripheral blood is a reliable proxy for the central compartment, despite conjecture that the latter would be more appropriate for detecting markers of endothelial dysfunction in pulmonary hypertension. If this is confirmed, further studies of endothelial status in pulmonary hypertension would require only minimally invasive sampling procedures.

CECs are a novel marker of endothelial damage, and their numbers correlate with other markers of endothelial function, such as flow-mediated dilation and von Willebrand factor and tissue plasminogen activator levels [27]. CEC counts are increased in coronary heart disease, renal vascular disease [28] and transplantation [29], and are a marker of progression and survival in acute coronary disease [30]. Very few data are available on CEC counts in pulmonary hypertension. BULL et al. [13] found that CEC numbers were increased in adults with various types of pulmonary hypertension. We recently showed that preoperative CEC numbers distinguished two groups of children with PAH secondary to congenital heart disease, namely those with markedly increased CEC numbers at baseline, in whom PAH became irreversible after surgery, and those with low CEC counts and reversible PAH [14]. 

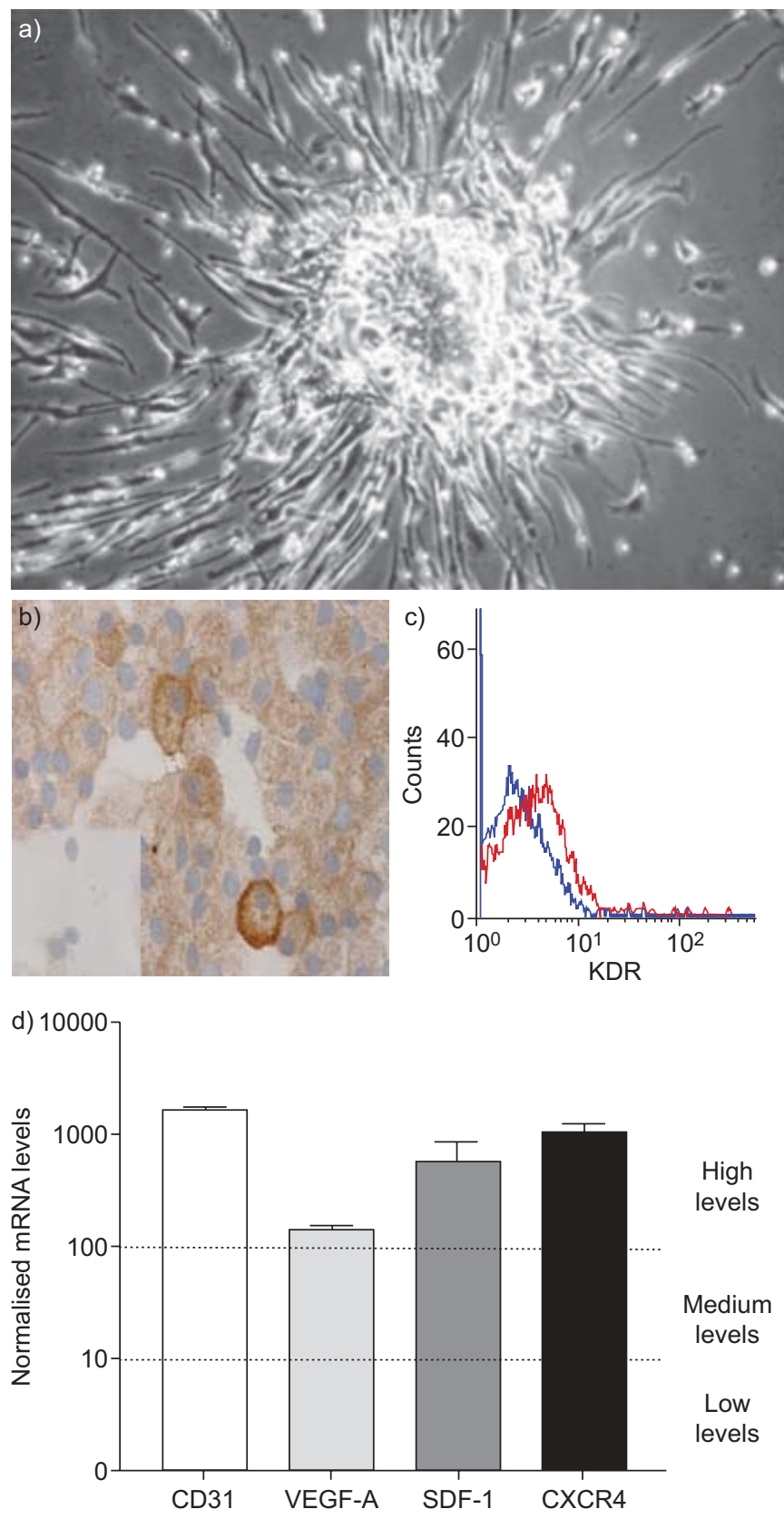

The latter study established CEC as a biomarker with strong prognostic value in this setting. For CEC quantification in the present study, it should be noted that we discarded the first $\mathrm{mL}$ of blood in order to avoid collecting endothelial cells dislodged by puncture.

CEC counts were increased in subjects with PAH and normal in patients with CTEPH. In addition, we found no correlation between the CEC count and haemodynamic parameters ( $\bar{P}$ pa, PVR and cardiac index) in either patient group. It is also important to note that the two groups were comparable in terms of haemodynamic and clinical parameters (table 1).

Taken together, these data suggest that high pulmonary pressures are not the main trigger of endothelial cell detachment from vessel walls and their subsequent circulation.

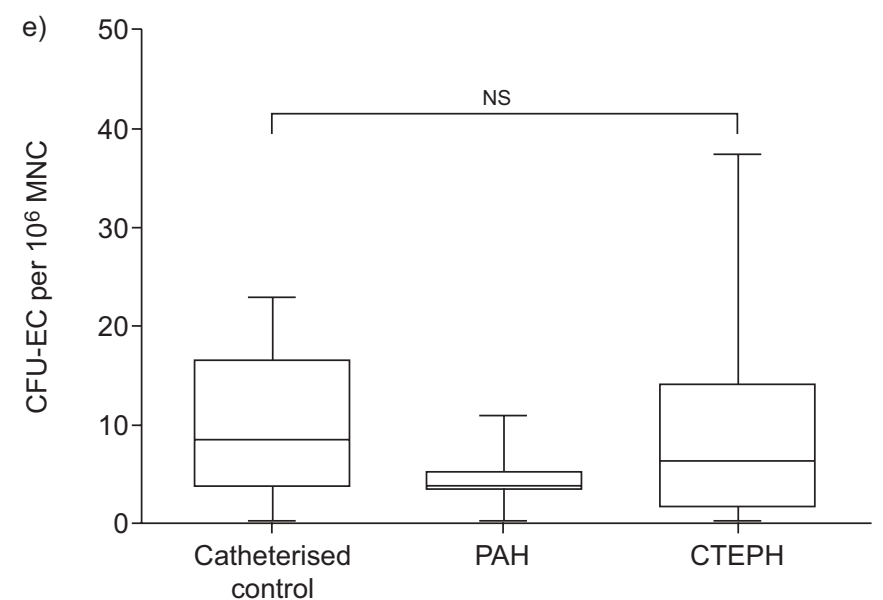

FIGURE 3. Endothelial cell colony-forming units (CFU-EC) quantification in pulmonary arterial hypertension (PAH) and chronic thromboembolic pulmonary hypertension (CTEPH). a) Representative CFU-EC. Note the central core of rounded cells with spindle-shaped cells sprouting through the periphery. b) CFU-EC immunohistological characterisation (von Willebrand factor; inset: isotypic control). c) Cytometric analysis of vascular endothelial growth factor receptor 2 (KDR). d) Real-time quantitative PCR (CD31, VEGF, SDF-1 and CXCR-4). e). Numbers of CFUEC colonies in PAH, counted with Endocultæ (StemCell Technologies, Vancouver, $\mathrm{BC}, \mathrm{Canada)}$. Results are the number of adherent cell clusters per $10^{6}$ mononuclear cells (MNCs). Results are mean $\pm \operatorname{SEM}(p=0.19$ and $p=0.48$, respectively, for $\mathrm{PAH}$ and $\mathrm{CTEPH}$ versus controls and $\mathrm{p}=0.36$ for $\mathrm{PAH}$ versus $\mathrm{CTEPH)}$. NS: nonsignificant.

Rather, the supernumerary CECs observed in PAH might result from increased vascular activation and/or remodelling. From a histopathological standpoint however, both disorders are associated with distal microvascular remodelling, which includes smooth muscle cell proliferation and arteriolar muscularisation, fibrosis, endothelial cell proliferation, intimal thickening and in situ thrombosis. Plexiform lesions have a similar histological aspect in idiopathic and secondary PAH. Also, actively proliferating endothelial cells are found in both forms of the disease, with no evidence of apoptosis. One particular characteristic of idiopathic PAH might, however, be critical, namely the nature of the endothelial cell expansion observed in plexiform lesions: it is monoclonal in idiopathic PAH $[6,7]$, whereas monoclonality has never been reported in other forms of PAH. Whether or not this reflects a particular 

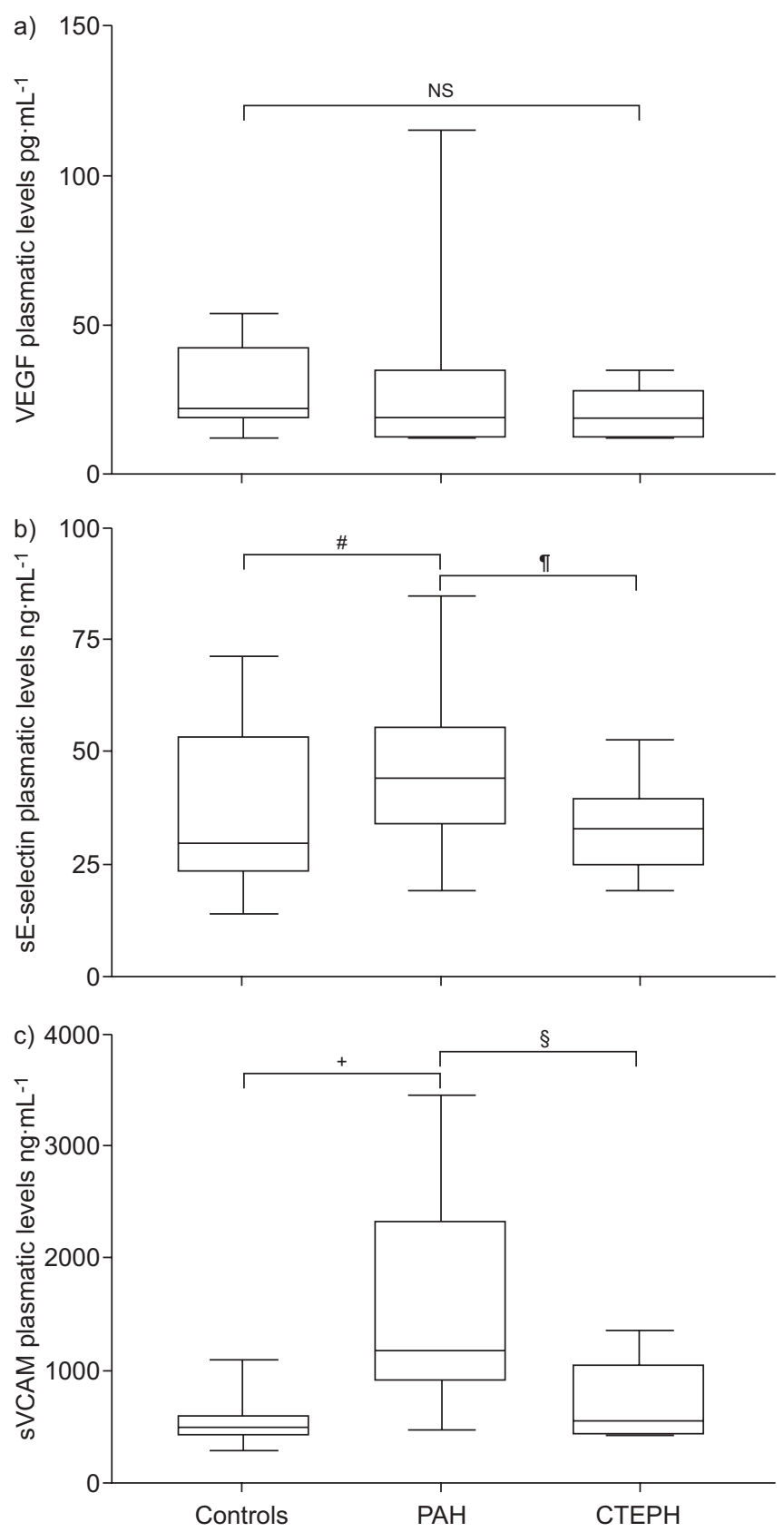

FIGURE 4. Plasma levels of vascular endothelial growth factor (VEGF), soluble E-selectin (sE-selectin) and soluble vascular cell adhesion molecules (SVCAM) in pulmonary arterial hypertension (PAH) and chronic thromboembolic pulmonary hypertension (CTEPH). Plasma levels of a) VEGF, b) sE-selectin and c) SVCAM were measured with ELISA. sE-selectin and SVCAM were increased in PAH. NS: nonsignificant. ${ }^{\#}: p=0.03 ;{ }^{\circ}: p=0.04 ;^{+}: p=0.006 ;{ }^{\varsigma}: p=0.02$.

capacity of endothelial cells to be shed from vessels in PAH remains to be investigated. Moreover, MOSER and BLOOR [9] conducted a comprehensive and systematic histopathological analysis of small pulmonary arteries in patients with CTEPH and concluded that these patients displayed a full range of distal histopathology changes, indicating advanced vessel remodelling, including plexiform lesions, smooth muscle cells hypertrophy and intimal proliferation/fibrosis. These lesions are also found in pulmonary arterial hypertension, without obstructive vessels specifically due to pulmonary embolism. We found that bosentan, an endothelin receptor antagonist, was associated with a decrease in CEC numbers after 3 months of treatment in all three patients we were able to study. It has been postulated that CECs are released upon uncontrolled endothelial cell proliferation or activation in pulmonary hypertension. By regulating vascular resistance, bosentan might reduce endothelial activation and, thus, CEC release.

Regarding the distinction between CECs and CD34+CD133+, the method we used to quantify CECs, based on their size and the number of coated beads, allowed us to distinguish CEC from CD146-expressing CD133+ cells. DELORME et al. [31] found that progenitor cells coexpressing CD146 and CD133, an antigen associated with immaturity, looked significantly different from mature CECs, which had morphological features of differentiated cells and were $>20 \mu \mathrm{m}$ in diameter. It is, therefore, unlikely that the CECs we counted using the immunomagnetic separation method included progenitor cells.

As endothelial progenitor cells are involved in healing processes [15], and as neoangiogenesis is consistently observed in $\mathrm{PAH}$, we suspected that endothelial progenitor cells numbers might be elevated in this setting. Because of the observed endothelial cell monoclonality, and as endothelial progenitor cells exhibit clonogenic properties [32, 33], we postulated that they might be partly responsible for the endothelial proliferation observed in PAH. As there is no consensus method for accurately quantifying endothelial progenitors in small samples, we chose to quantify circulating CD34+CD133+ progenitor cells that comprise a subpopulation of endothelial progenitors, and have been described as the source of endothelial progenitor cells in culture [34-36]. In experimental models of hypoxia-induced PAH, endothelial progenitors appear to be involved in pulmonary vascular remodelling [37]. However, human studies have variously shown increased CD34+CD133+ numbers in patients with $\mathrm{PAH}$ [22] or no correlation between PAH and CD34+CD133+ [24]. In another study, numbers of endothelial progenitors isolated by cell culture were elevated in PAH [23]. In the present study, CD34+CD133+ and CFU-EC counts did not differ between the pulmonary hypertension and control groups (figs 2 and 3). Further studies are needed to confirm the observed lack of endothelial cell progenitor mobilisation in pulmonary hypertension, based on the assessment of different types of endothelial progenitor (CD34+CD133+ cells expressing KDR and/or CD146) and late-outgrowth endothelial progenitor cells obtained in culture. However, it is noteworthy that, although angiogenic and inflammatory marker levels have been found to correlate with the abundance of CD34+CD133+ and endothelial progenitors [38, 39], VEGF levels were similar in our patient groups and controls, further supporting the lack of CEC progenitor mobilisation. The VEGF levels found here are similar to those found in healthy male and female volunteers [40]. In the present study, VEGF was quantified in plasma and not in serum, in order to rule out any potential influence of platelet VEGF granule content release. Indeed, it has been reported that VEGF of platelet origin can interfere with the pathophysiology of pulmonary hypertension [41] and with VEGF quantification in serum [42]. 
The source of the endothelial cells involved in the vascular remodelling associated with pulmonary hypertension is unclear. One possibility is that vascular progenitors may be recruited from a stem cell niche within the lung, as opposed to resulting from systemic progenitor mobilisation. Finally, soluble E-selectin and sVCAM, two adhesion molecules inducible on endothelial cells, have also been linked to endothelial damage and/or activation. Recently, E-selectin was described as a pivotal molecule for endothelial progenitor cell homing [43], whereas sVCAM plasma levels in pulmonary hypertension have been shown to correlate with endothelial activation reflected by endothelial microparticle detection [44]. The elevated plasma levels of soluble E-selectin and sVCAM that we observed in PAH could, along with the excess of CECs, reflect intense endothelial activation, which might participate in local pulmonary recruitment of progenitor cells; however, this needs to be demonstrated in larger studies.

In conclusion, this study shows that levels of circulating biomarkers of endothelial activation differ markedly between patients with $\mathrm{PAH}$ and patients with CTEPH of comparable severity. The value of CEC as a biomarker of clinical outcome and/or the treatment response in $\mathrm{PAH}$ remains to be determined.

\section{STATEMENT OF INTEREST}

None declared.

\section{ACKNOWLEDGEMENTS}

This work was supported by research grants from INSERM, the Leducq TransAtlantic Network of Excellence on Atherothrombosis Research (Grant 04CVD01) and Chancellerie des Universités (Legs Poix) (Paris, France).

\section{REFERENCES}

1 Simonneau G, Robbins IM, Beghetti M, et al. Updated clinical classification of pulmonary hypertension. J Am Coll Cardiol 2009; 54: S43-S54.

2 Leuchte HH, Behr J. Iloprost for idiopathic pulmonary arterial hypertension. Expert Rev Cardiovasc Ther 2005; 3: 215-223.

3 Humbert M, Morrell NW, Archer SL, et al. Cellular and molecular pathobiology of pulmonary arterial hypertension. J Am Coll Cardiol 2004; 43: 13S-24S.

4 Morrell NW, Adnot S, Archer SL, et al. Cellular and molecular basis of pulmonary arterial hypertension. J Am Coll Cardiol 2009; 54: S20-S31.

5 Cool CD, Stewart JS, Werahera $\mathrm{P}$, et al. Three-dimensional reconstruction of pulmonary arteries in plexiform pulmonary hypertension using cell-specific markers. Evidence for a dynamic and heterogeneous process of pulmonary endothelial cell growth. Am J Pathol 1999; 155: 411-419.

6 Lee SD, Shroyer KR, Markham NE, et al. Monoclonal endothelial cell proliferation is present in primary but not secondary pulmonary hypertension. J Clin Invest 1998; 101: 927-934.

7 Rai PR, Cool CD, King JA, et al. The cancer paradigm of severe pulmonary arterial hypertension. Am J Respir Crit Care Med 2008; 178: 558-564.

8 Lang IM, Klepetko W. Chronic thromboembolic pulmonary hypertension: an updated review. Curr Opin Cardiol 2008; 23: 555-559.

9 Moser KM, Bloor CM. Pulmonary vascular lesions occurring in patients with chronic major vessel thromboembolic pulmonary hypertension. Chest 1993; 103: 685-692.
10 Levy M, Maurey C, Celermajer DS, et al. Impaired apoptosis of pulmonary endothelial cells is associated with intimal proliferation and irreversibility of pulmonary hypertension in congenital heart disease. J Am Coll Cardiol 2007; 49: 803-810.

11 Sabatier F, Camoin-Jau L, Anfosso F, et al. Circulating endothelial cells, microparticles and progenitors: key players towards the definition of vascular competence. J Cell Mol Med 2009; 13: 454-471.

12 Woywodt $\mathrm{A}$, Blann $\mathrm{AD}$, Kirsch $\mathrm{T}$, et al. Isolation and enumeration of circulating endothelial cells by immunomagnetic isolation: proposal of a definition and a consensus protocol. J Thromb Haemost 2006; 4: 671-677.

13 Bull TM, Golpon H, Hebbel RP, et al. Circulating endothelial cells in pulmonary hypertension. Thromb Haemost 2003; 90: 698-703.

14 Smadja DM, Gaussem P, Mauge L, et al. Circulating endothelial cells: a new candidate biomarker of irreversible pulmonary hypertension secondary to congenital heart disease. Circulation 2009; 119: 374-381.

15 Smadja DM, Cornet A, Emmerich J, et al. Endothelial progenitor cells: characterization, in vitro expansion, and prospects for autologous cell therapy. Cell Biol Toxicol 2007; 23: 223-239.

16 Hill JM, Zalos G, Halcox JP, et al. Circulating endothelial progenitor cells, vascular function, and cardiovascular risk. N Engl J Med 2003; 348: 593-600.

17 Palange P, Testa U, Huertas A, et al. Circulating haemopoietic and endothelial progenitor cells are decreased in COPD. Eur Respir J 2006; 27: 529-541.

18 Zhao YD, Courtman DW, Ng DS, et al. Microvascular regeneration in established pulmonary hypertension by angiogenic gene transfer. Am J Respir Cell Mol Biol 2006; 35: 182-189.

19 Nagaya N, Kangawa K, Kanda M, et al. Hybrid cell-gene therapy for pulmonary hypertension based on phagocytosing action of endothelial progenitor cells. Circulation 2003; 108: 889-895.

20 Zhao YD, Courtman DW, Deng Y, et al. Rescue of monocrotalineinduced pulmonary arterial hypertension using bone marrowderived endothelial-like progenitor cells: efficacy of combined cell and eNOS gene therapy in established disease. Circ Res 2005; 96: 442-450.

21 Wang XX, Zhang FR, Shang YP, et al. Transplantation of autologous endothelial progenitor cells may be beneficial in patients with idiopathic pulmonary arterial hypertension: a pilot randomized controlled trial. J Am Coll Cardiol 2007; 49: 1566-1571.

22 Asosingh K, Aldred MA, Vasanji A, et al. Circulating angiogenic precursors in idiopathic pulmonary arterial hypertension. Am J Pathol 2008; 172: 615-627.

23 Junhui Z, Xingxiang W, Guosheng F, et al. Reduced number and activity of circulating endothelial progenitor cells in patients with idiopathic pulmonary arterial hypertension. Respir Med 2008; 102: 1073-1079.

24 Diller GP, van Eijl S, Okonko DO, et al. Circulating endothelial progenitor cells in patients with Eisenmenger syndrome and idiopathic pulmonary arterial hypertension. Circulation 2008; 117: 3020-3030.

25 Badesch DB, Champion HC, Sanchez MA, et al. Diagnosis and assessment of pulmonary arterial hypertension. J Am Coll Cardiol 2009; 54: S55-S66.

26 Galie N, Hoeper MM, Humbert M, et al. Guidelines for the diagnosis and treatment of pulmonary hypertension. Eur Respir J 2009; 34: 1219-1263.

27 Boos CJ, Blann AD, Lip GY. Assessment of endothelial damage/ dysfunction: a focus on circulating endothelial cells. Methods Mol Med 2007; 139: 211-224.

28 Yao G, Liu ZH, Zheng C, et al. Evaluation of renal vascular lesions using circulating endothelial cells in patients with lupus nephritis. Rheumatology (Oxford) 2008; 47: 432-436.

29 Widemann A, Sabatier F, Arnaud L, et al. CD146-based immunomagnetic enrichment followed by multiparameter flow cytometry: 
a new approach to counting circulating endothelial cells. J Thromb Haemost 2008; 6: 869-876.

30 Lee KW, Lip GY, Tayebjee M, et al. Circulating endothelial cells, von Willebrand factor, interleukin-6, and prognosis in patients with acute coronary syndromes. Blood 2005; 105: 526-532.

31 Delorme B, Basire A, Gentile C, et al. Presence of endothelial progenitor cells, distinct from mature endothelial cells, within human CD146+ blood cells. Thromb Haemost 2005; 94: 1270-1279.

32 Ingram DA, Mead LE, Tanaka $\mathrm{H}$, et al. Identification of a novel hierarchy of endothelial progenitor cells using human peripheral and umbilical cord blood. Blood 2004; 104: 2752-2760.

33 Ingram DA, Caplice NM, Yoder MC. Unresolved questions, changing definitions, and novel paradigms for defining endothelial progenitor cells. Blood 2005; 106: 1525-1531.

34 Sharpe EE 3rd, Teleron AA, Li B, et al. The origin and in vivo significance of murine and human culture-expanded endothelial progenitor cells. Am J Pathol 2006; 168: 1710-1721.

35 Timmermans F, Van Hauwermeiren F, De Smedt M, et al. Endothelial outgrowth cells are not derived from CD133+ cells or CD45+ hematopoietic precursors. Arterioscler Thromb Vasc Biol 2007; 27: 1572-1579.

36 Case J, Mead LE, Bessler WK, et al. Human CD34+AC133+VEGFR-2+ cells are not endothelial progenitor cells but distinct, primitive hematopoietic progenitors. Exp Hematol 2007; 35: 1109-1118.

37 Davie NJ, Crossno JT Jr, Frid MG, et al. Hypoxia-induced pulmonary artery adventitial remodeling and neovascularization: contribution of progenitor cells. Am J Physiol Lung Cell Mol Physiol 2004; 286: L668-L678.

38 Marboeuf P, Corseaux D, Mouquet F, et al. Inflammation triggers colony forming endothelial cell mobilization after angioplasty in chronic lower limb ischemia. J Thromb Haemost 2008; 6: 195-197.

39 George J, Goldstein E, Abashidze S, et al. Circulating endothelial progenitor cells in patients with unstable angina: association with systemic inflammation. Eur Heart J 2004; 25: 1003-1008.

40 Smadja DM, Gaussem P, Roncal C, et al. Arterial and venous thrombosis are associated with different angiogenic cytokine patterns in patients with the antiphospholipid syndrome. Lupus 2010; 19: 837-843.

41 Eddahibi S, Humbert M, Sediame S, et al. Imbalance between platelet vascular endothelial growth factor and platelet-derived growth factor in pulmonary hypertension. Effect of prostacyclin therapy. Am J Respir Crit Care Med 2000; 162: 1493-1499.

42 Papaioannou AI, Zakynthinos E, Kostikas K, et al. Serum VEGF levels are related to the presence of pulmonary arterial hypertension in systemic sclerosis. BMC Pulm Med 2009; 9: 18.

$43 \mathrm{Oh} \mathrm{IY}$, Yoon $\mathrm{CH}$, Hur J, et al. Involvement of E-selectin in recruitment of endothelial progenitor cells and angiogenesis in ischemic muscle. Blood 2007; 110: 3891-3899.

44 Bakouboula B, Morel O, Faure A, et al. Procoagulant membrane microparticles correlate with the severity of pulmonary arterial hypertension. Am J Respir Crit Care Med 2008; 177: 536-543. 